\title{
Attraction of Wild Crops to Arthropods around the Farming Land of Chrysanthemum indicum, Batu, East Java, Indonesia
}

\author{
Minahanggari Mukti, Bagyo Yanuwiadi, Setijono Samino \\ Biology Postgraduate, University of Brawijaya, Indonesia
}

\begin{abstract}
Objectives of the research were to analyze diversities and compositions of Arthropod on wild crops around the farming land of Chrysanthemum indicum and functional status of the Arthropods. The research was conducted at the farming land of Chrysanthemum indicum, in greenhouse and non-greenhouse at Bumiaji Subdistrict, Batu. Observation on Arthropods used sample plots, $1 \times 1 \mathrm{~m} 2$, by direct observation method on four variations of time. Collecting data was done by counting the whole Arthropods, which visited the plots of the tested-crops. Community structure of the Arthropods is determined using Shannon-Wienner Diversity Index, while Bray-Curtis Similarity Index is used to compare the composition of Arthropods in greenhouse and nongreenhouse. The arthropods abundance in both farming lands was compared using Kuskall Wallis's and Mann Whitney's tests. Results of the research showed that community of Arthropods on Sonchus arvensis L. has the highest varieties, both at the greenhouse and non-greenhouse, by diversity index (H') values 1.871 and 1.516, respectively. Based on Bray-Curtis Similarity Index, the similarity value of Arthropod's community between both lands was about 0.5928. Based on results of Kruskall Wallis' and Mann Whitney's tests, greenhouse and non-greenhouse treatments have not affected on the arthropods abundance.
\end{abstract}

Keywords: abundance, arthropods, habitat management, pest, tested crop

\section{INTRODUCTION}

The introduction of Chrysanthemum indicum, however, is profitable from the economic aspect, but it indirectly brings about negative impact on ecosystem. Leaf borer of Liriomyza huidobrensis emerged for the first time in Indonesia in 1994, which was introduced by Chrysanthemum indicum [1]. Such pest has been able to adapt, grow, and develop in any condition, so that it has not only infected Chrysanthemum indicum, but also some vegetables as well in Indonesia. Such organism is difficult to be controlled due to the natural enemy was not gone along with the introduced organism; therefore the appropriate technology to control such pest has not been found out [2].

The extensive breeding of Chrysanthemum indicum in Batu, East Java, Indonesia, requires a solution that could overcome the pest problem by empowering biotic factors in that agro-ecosystem through habitat management. Such habitat management is intended to improve the roles of wild crops as refugee around the farming land that could conserve the natural enemy [3]. Wild crops are potential as refugee for natural enemy because they will be able to provide supplemental foods resources, resting place, reproduction place, and shelter from any worst condition [4]. The existence of wild crops on farming land is essential to increase variability of insects [5]. Different kinds of crop in a given land would cause the insects keep in abundant and in certain varieties. Besides that, types of crop, which construct the land, have affected dynamic of the insects' population and their interactions with the natural enemies [6].

Research by Rauf [7] and Rauf et al. [8] proved the attraction of wild crops, such as Ageratum conyzoides, Ilysanthes antipoda Merr., Poligonum longisetum, Amarantus spinosus L., and alike for the leaf borer of L. huidobrensis. Meanwhile, research by Rasminah and Rohman [3] showed that Synedrella nodiflora, Centella asiatica, Setaria sp., Borreria repens, Arachis pentoii, and their combinations have been able to increase Curinus, Oxyopes, and Hymenopus as generalist predator, a pest on tea leaf, Empoasca sp. Objectives of the research was to analyze diversity and composition of Arthropods on wild crops around the farming land of Chrysanthemum indicum in the greenhouse and non-greenhouse, as well as functional status of the related Arthropods.

\section{MATERIAL AND METHOD}

The research conducted from November 2012 to July 2013 at the farming land of Chrysanthemum indicum, in greenhouse and non-greenhouse at Bumiaji Village, Bumiaji Subdistrict, Batu. The tested crops of the research included wild crops, which are easily found around the farming land of Chrysanthemum indicum, such as Sonchus arvensis L. Vahl. (Sa), Drymaria cordata Wild. (Dc), Rhinacantus nasutus (L.) Kurz. (Rn), and Oxalis cornicilata Linn. (Oc). Those crops are planted on the area of $1 \mathrm{~m}^{2}$. Data collection was done through direct observation by calculating types and number of individuals, in this case was Arthropods, which visited each plot. Meanwhile, data collection on Arthropods used direct method, which was done in four variations of 
time, such as 07.00-08.15, 09.00-10.15, 12.00-13.15 and 15.00-16.15 WIB [9, 10]. Besides that, measurement of the abiotic factors included temperature, humidity, wind velocity, and light intensity. Index [11].

Comparison of the Arthropods community structure is determined using Shannon-Wienner Diversity

$\mathrm{H}^{\prime}=$ Shannon - Wienner Diversity Index

$$
\mathrm{H}=-\sum_{\mathrm{i}}^{\mathrm{s}} \mathrm{Pi}^{2} \log \mathrm{Pi}
$$

pi $=$ Proportion of the-i species toward total sum $(\mathrm{ni} / \mathrm{N})$

$\mathrm{s}=$ Total sum of species in community

In order to compare composition of Arthropods at the greenhouse and non-greenhouse, the Similarity Index of Bray-Curtis is applied.

$$
\mathrm{IBC}=1-\frac{\sum\left|\mathrm{x}_{\mathrm{i}}-\mathrm{y}_{\mathrm{i}}\right|}{\sum\left(\mathrm{x}_{\mathrm{i}}-\mathrm{y}_{\mathrm{i}}\right)}
$$

IBC $=$ Bray-Curtis Similarity Index

$\mathrm{xi} \quad=$ Number of individual of the-i on sample of community $\mathrm{X}$

yi $\quad$ Number of individual of the-i on sample of community $\mathrm{Y}$

The whole data was tabulated and compiled using Microsoft Excel 2007 program and was analyzed using PAST program. In order to compare the abundant Arthropods, non-parametric test was applied using Kruskall Wallis' and Mann Whitney's tests using SPSS 16 program.

\section{RESULT AND DISCUSSION}

Comparison between compositions and abundant Arthropods on the tested crops at the farming land of Chrysanthemum indicum is presented in Table 1.

\begin{tabular}{|c|c|c|c|c|c|c|c|c|}
\hline \multicolumn{9}{|c|}{ indicum } \\
\hline \multirow[b]{2}{*}{ Tested Crops } & \multicolumn{4}{|c|}{ Greenhouse } & \multicolumn{4}{|c|}{ Non-greenhouse } \\
\hline & $\begin{array}{l}\text { Number of } \\
\text { Taxon }\end{array}$ & $\begin{array}{l}\text { Number of } \\
\text { Individual }\end{array}$ & $\begin{array}{c}\text { Relative } \\
\text { Abundant }\end{array}$ & $\begin{array}{l}\text { IVI } \\
(\%)\end{array}$ & $\begin{array}{l}\text { Number } \\
\text { of Taxon }\end{array}$ & $\begin{array}{l}\text { Number of } \\
\text { Individual }\end{array}$ & $\begin{array}{l}\text { Relative } \\
\text { Abundant }\end{array}$ & $\begin{array}{l}\text { IVI } \\
(\%)\end{array}$ \\
\hline Sonchus arvensis L. Vahl. & 15 & 299 & $\begin{array}{c}\text { Formicidae } \\
(38.15 \%)\end{array}$ & 47.43 & 10 & 152 & $\begin{array}{c}\text { Formicidae } \\
(51.97 \%)\end{array}$ & 65.31 \\
\hline Drymaria cordata Wild. & 11 & 159 & $\begin{array}{c}\text { Formicidae } \\
(35.57 \%)\end{array}$ & 52.96 & 10 & 149 & $\begin{array}{c}\text { Aleyrodidae } \\
(80.50 \%)\end{array}$ & 104.03 \\
\hline $\begin{array}{l}\text { Rhinachanthus nasutus } \\
\text { (L.) Kurz }\end{array}$ & 11 & 322 & $\begin{array}{c}\text { Aleyrodidae } \\
(68.01 \%)\end{array}$ & 82.83 & 10 & 244 & $\begin{array}{c}\text { Aleyrodidae } \\
(91.39 \%)\end{array}$ & 112.45 \\
\hline Oxalis corniculata $\mathrm{L}$. & 9 & 199 & $\begin{array}{c}\text { Aleyrodidae } \\
(34.67 \%)\end{array}$ & 50.67 & 6 & 107 & $\begin{array}{c}\text { Aleyrodidae } \\
(85.98 \%)\end{array}$ & 114.55 \\
\hline Control & 2 & 14 & $\begin{array}{c}\text { Formicidae } \\
(78.57 \%)\end{array}$ & 145.24 & 2 & 3 & $\begin{array}{c}\text { Formicidae } \\
(66.67 \%)\end{array}$ & 116.67 \\
\hline
\end{tabular}

Table 1. Composition and abundant arthropods on the tested crops at the farming land of Chrysanthemum

Based on Table 1, comparison between compositions and abundant Arthropods at the greenhouse and non-greenhouse with four tested crops shows different results. Out of four tested crops at the greenhouse, number of taxon and number of individual for Arthropods were higher than at the non-greenhouse. Each type of the tested crop was assumed to transfer specific signal, which was recognized by diverse types of Arthropods at the farming land of Chrysanthemum indicum. Such signal derived from secondary chemical compounds, which directly and indirectly, affected habits in eating, moving, and laying eggs. Such habits will automatically affect behavior of the predator as well as parasitoid in selecting crops as habitat of the prey.

The highest abundant of Arthropods on the tested crops at both farming lands were dominated by pests. There were nine families of pest at the greenhouse, such as Pyrgomorphidae, Cicadulidae, Sciaridae, Agromyzidae, Aleyrodidae, Tephritidae, Miridae, Acrididae, and Phoridae. Meanwhile, at the non-greenhouse, seven families of pest were found, such as Cicadulidae, Sciaridae, Agromyzidae, Aleyrodidae, Aphididae, Phoridae and Thripidae. While the natural enemies, which visited the tested crops at the greenhouse, such as Formicidae, Lycosidae, Araneidae, and Coccinellidae. At the non-greenhouse included Formicidae, Dolichopodidae, Araneidae, Lycosidae, Coccinellidae and Staphylinidae. Other Arthropods, which visited the tested crops at the farming land of Chrysanthemum indicum, included the pollinators, such as Aphidae and Syrphidae. As a whole, comparison between pests or Arthropod phytophagus and the natural enemies, as well as others are presented in Figure 1. 


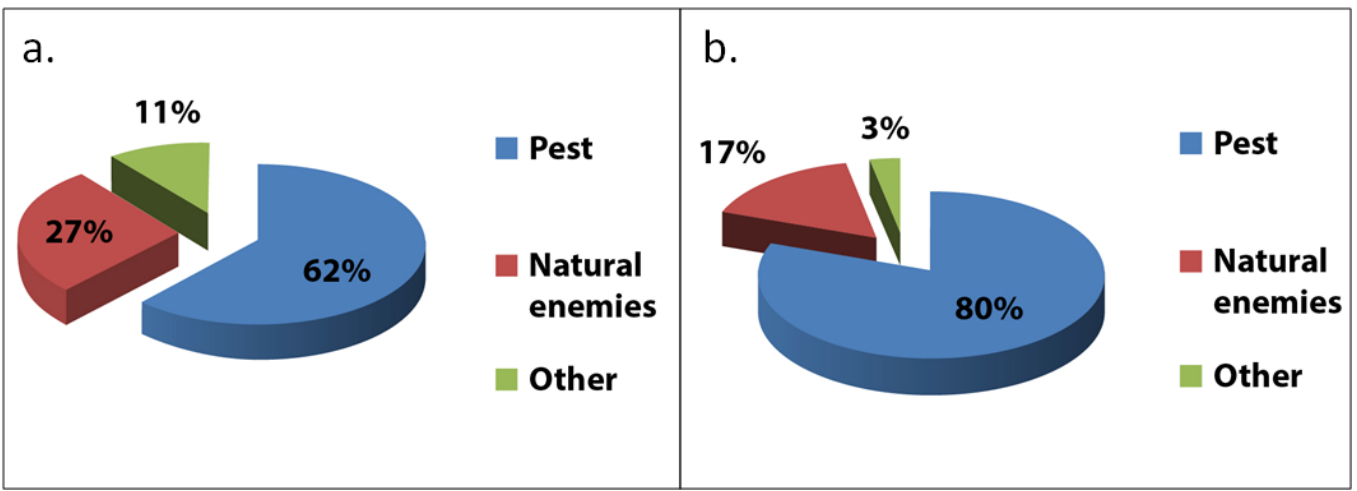

Figure 1. Relative abundant of the pests, natural enemies, and others in (a) Greenhouse and (b) Non-greenhouse

The natural enemies required alternative feed sources, which are always available to survive, due to the existence of prey and crops that are not always available at the farming land. Existence of non-croping area at the breeding land is highly required by the natural enemies [12]. As well as at the farming land of Chrysanthemum indicum, existence of the natural enemy can be maintained by providing non-cropping area. Non-cropping area is assumed to keep the pest species below the economic threshold and reduce the application of pesticides [10]. In simple, the increasing of crops sources at the farming land or non-cropping area can be done by being tolerant to the existence of some wild crops [4].

The variance levels of Arthropods on the tested crops at both farming lands were varied from low to medium, based on Diversity Index of Shannon-Wienner (Fig. 2). Sonchus arvensis L. has the highest variance at both greenhouse and non-greenhouse by the Diversity Index values $\left(\mathrm{H}^{\prime}\right)$ are 1.871 and 1.516, respectively. It shows that the crops are potential to be developed as refugee at the farming land of Chrysanthemum indicum. Meanwhile, the Diversity Index values of the Arthropods on the tested crops are relatively higher than on the control or without crops. It proves that the increasing variance of the crop types would be able to increase variance and abundance of the Arthropods.

Landis et al. [12] stated that variance manipulation on crops at the farming land would be able to affect the potential natural enemies as the biological controlling agent. Specific habitat on the farming landscape could be acted as corridor to increase population exchange between the planting area and non-planting area. Planting the corridor of flowering plants has provided alternative feed sources for the natural enemies along the season and maintains the dispersal of natural enemies, which could reduce number of pests on the farming land.

As a whole, the greenhouse has higher variance values than non-greenhouse. It is possibly caused by the environmental condition at the greenhouse, which is relatively stable. Besides that, interference on the Arthropod at the greenhouse is relatively less in comparison with at non-greenhouse.
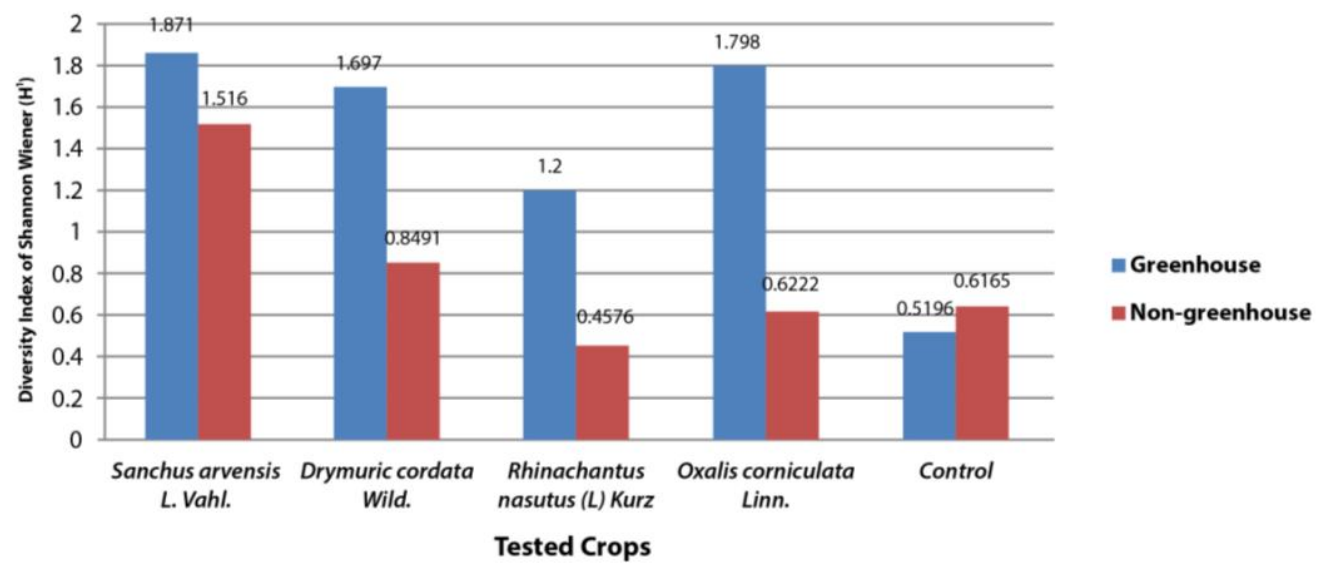

Figure 2. Diversity Index of Shannon-Wiener Arthropod on the tested crops at the farming land of Chrysanthemum indicum

Based on calculation of the Similarity Index by Bray-Curtis, the equality value of the Arthropods' community between both farming lands is 0.5928 . The value describes that the farming lands at the greenhouse and non-greenhouse tends to have identical community of Arthropods. It shows that types of the Arthropods at both farming lands tend to visit the same wild plants. Open-greenhouse enables the migration of insects from inside of the greenhouse to go out and on the contrary. Hara dan Matayoshi [13] stated that in Hawaii, most of Chrysanthemum indicum, which are bred in a greenhouse that is open at the side part, and as a result is the migration of insects, such as parasitoid and predator from inside of the greenhouse and go out. 
Results of Kruskall Wallis' and Mann Whitney's tests showed that GH and NGH treatments have no effect on number of the incoming Arthropods. It means that numbers of the incoming Arthropods are equal at both locations of the observation. It has been shown by Asymp. Sig (0.126) > 0.05. Meanwhile, it has been proved that wild plants affect on number of the incoming Arthoropods. It has been shown by Asymp. Sig $(0.000)<0.05$, which means that number of the incoming Arthropods, which visit on each tested crop, is different. Meanwhile, results of the test for the observation time show that the observation time does not affect on number of the incoming Arthropods. It has been shown by Asymp. Sig (0.126)>0.05, and it can be see that Arthropods are active all the time at the farming land of Chrysanthemum indicum.

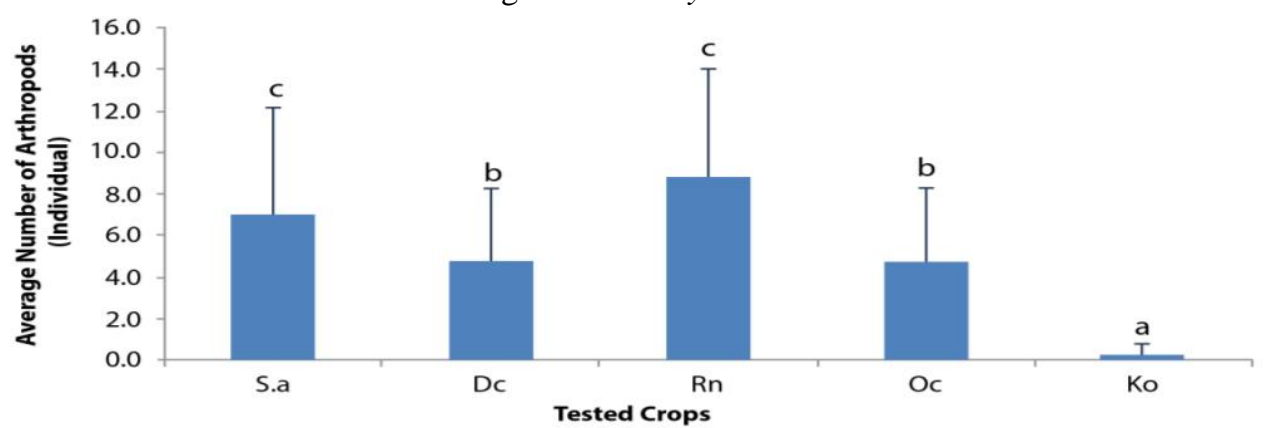

Figure 3. Average number of Arthropods' visits on the tested crops.

$\mathrm{Sa}=$ Sonchus arvensis $\mathrm{L}$. Vahl.; Dc $=$ Drymaria cordata Wild.; $\mathrm{Rn}=$ Rhinacantus nasutus $(\mathrm{L}$.$) Kurz; Oc =$ Oxalis corniculata Linn.; C = Control

On average, numbers of Arthropod's visits on the tested crops, based on Kruskall Wallis and Mann Whitney, are presented in Fig. 3. On average, number of the Arthropods' visits on Sonchus arvensis L. Vahl. and Rhinachanthus nasutus (L.) Kurz are identical, in which both of them are the most attractive to Arthropods. Meanwhile, average numbers of the Arthropods' visits on Drymaria cordata Wild. and Oxalis corniculata L. are identical. However, control has the lowest contribution to the Arthropods' visit. The results show that Sonchus arvensis L. Vahl. and Rhinachanthus nasutus (L.) Kurz play interplaceable roles in attracting Arthropods, as well as Drymaria cordata Wild. and Oxalis corniculata L.

\section{CONCLUSION}

Composition and abundant of Arthropods are different for each type of the tested crop. Sonchus arvensis L. has the highest variances at the greenhouse and non-greenhouse with Diversity Index (H') values are 1.871 and 1.516, respectively. The similarity value of the Arthropod community, based on Bray-Curtis Index, between both lands is about 0.5928 . Percentage of the natural enemy, which attract to the tested crops at the greenhouse is about $27 \%$, while at non-greenhouse is about $17 \%$.

\section{Acknowledgement}

The writer would like to express her gratitude to God and special thanks to Drs. Fatcur Rohman, M.Si and Amin Setyo Leksono, S.Si., M.Si., Ph.D for their supports and corrections, as well as to Ayu Raisa Khairun Nisa', Prayogo Richi NM., Makinun Amin, Susi Mindarti for their assistances during the research.

\section{REFERENCES}

[1] B.M. Shepard and S.A.R. Braun, Seasonal incidence of Liriomyza huidobrensis (Diptera: Agromyzidae) and its parasitoids on vegetables in Indonesia, International Journal of Pest Management, 44(1), 2010.

[2] K. Untung, Preface of integrated pest management (Yogyakarta: Gadjah Mada University Press, 2006).

[3] S. Rasminah and F. Rohman, Refugee plants increased generalits predator in tea plantation at Wonosari, Malang-Indonesia, American-Eurasian Journal of Sustainable Agriculture, 6(1), 2012, 51-54.

[4] D.A. Landis, S.D. Wratten, and G.M. Gurr, Habitat management to conserve natural enemies of arthropod pests in agriculture, Annual Review of Entomology, 45, 2000, 175-201.

[5] Knauer, Ökologie und landwirschaft, situatiom konflikte (Stutgart: Losungen, 1993).

[6] M.D. Hunter, Landcsape structure, habitat fragmentation, and the ecology of insect, Agricultural and Forests Entomology, 4, 2002, $159-166$.

[7] A. Rauf, Liriomyza: newcomer pest in Indonesia, Bul. HPT, 8, 1995, 46-48.

[8] A. Rauf, B.M. Shepard, and M.W. Johnson, Leafminers in vegetables, ornamental plants and weeds in Indonesia: surveys of host crops, species composition and parasitoids, International Journal of Pest Management, 46, 2000, 257-266.

[9] B, Purwatiningsih, The role of cover crops and social perception to support the pollinator insects on apple's flower in Poncokusumo Malang, Thesis, Universitas of Brawijaya, Malang, Indonesia, 2012.

[10] W. Nentwig, Weedy plant species and their beneficial arthropods: potential for manipulation in field crops, in Pickett CH, Bugg RL (eds), Enhancing Biological Control, (Berkeley: University of California Press, 1999) 49-71.

[11] P. Michael, Ecological Methods for Field and Laboratory Investigation (Tata McGraw-Hill Publishing Company Limited, 1984).

[12] D.A. Landis, F.D. Menalled, A.C. Costamagna, A.C., and T.K. Wilkunson, Manipulating plant resource to enhance beneficial arthropods in agricultural landscape, Weed Science, 53, 2005, 902-908.

[13] A.H. Hara and S. Matayoshi, Parasitoids and predators of insect pests on chrysanthemum in Hawaii, Proc. Hawaiian Entomological Society, 30, 1990. 